\title{
IMPLEMENTASI FASILITAS INTELLIGENT TRANSPORTATION SYSTEM (ITS) DI KOTA PALANGKA RAYA
}

\author{
Devia $^{1}$, Prihanika ${ }^{2}$ \\ Fakultas Teknik, Universitas Palangka Raya \\ ${ }^{1}$ deviadev90@gmail.com, ${ }^{2}$ prihanika83@gmail.com
}

\begin{abstract}
ABSTRAK
Pergerakan orang dan barang yang meningkat sejalan dengan pertumbuhan ekonomi pada masyarakat. Hal ini menyebabkan adanya potensi peningkatan aktivitas transportasi di Kota Palangka Raya sehingga perlu upaya peningkatan sarana dan prasarana transportasi yang memadai. Penerapan fasilitas Intelligent Transportation System (ITS) di Kota Palangka Raya yang berbasis teknologi diperlukan agar pengelolaan sistem transportasi menjadi lebih efektif dan efisien. Tulisan ini memberikan gambaran penerapan fasilitas dan jenis ITS yang ada di Kota Palangka Raya dan memberikan rekomendasi pemanfaatan fasilitas ITS yang baru ataupun mengoptimalkan teknologi yang ada agar fasilitas ITS dapat dimanfaatkan oleh stakeholder dalam manajemen lalu lintas dan sistem transportasi di Kota Palangka Raya. Berdasarkan hasil pengamatan penerapan ITS di Kota Palangka Raya diterapkan untuk meningkatkan pelayanan kinerja simpang dan ruas jalan. Jenis fasilitas ITS yaitu Area Traffic Control System (ATCS) yaitu sistem kendali lalu lintas kendaraan pada simpang bersinyal untuk meningkatkan kecepatan perjalanan dan waktu tempuh sehingga tundaan dalam perjalanan dapat diminimalkan. Diharapkan juga implementasi ITS di Kota Palangka Raya juga dapat mengoptimalkan kinerja angkutan umum dan keselamatan lalu lintas serta adanya kerjasama antara stakeholder agar peningkatan sistem transportasi terintegrasi dengan baik.
\end{abstract}

Kata Kunci: intelligent transport system, ATCS, kinerja simpang, sistem transportasi

\begin{abstract}
The movement of people and goods is increasing in line with economic growth in society. This causes the potential for increased transportation activities in the City of Palangka Raya so it needs efforts to improve adequate transportation facilities and infrastructure. The application of technology-based Intelligent Transportation System (ITS) in Palangka Raya City is needed so that the management of the transportation system becomes more effective and efficient. This paper provides an overview of the application of ITS facilities and types in Palangka Raya City and provides recommendations for the use of new ITS facilities or optimizing existing technology so that ITS facilities can be utilized by stakeholders in traffic management and transportation systems in Palangka Raya City.Based on observations of the application of ITS in the City of Palangka Raya is applied to improve the performance of intersections and road services. The type of ITS facility is the Area Traffic Control System (ATCS), which is a vehicle traffic control system at the signal intersection to increase travel speed and travel time so that delays in travel can be minimized. It is also expected that the implementation of ITS in Palangkaraya City can also optimize the performance of public transport and traffic safety as well as the collaboration between stakeholders so that the improvement of the integrated transportation system can be well integrated.
\end{abstract}

Keywords: intelligent transport system, ATCS, performance intersections, transportation systems 


\section{PENDAHULUAN}

Transportasi adalah proses pemindahan barang atau orang yang digunakan untuk menunjang atau mendorong perekonomian suatu daerah. Satu diantara keberhasilan pembangunan suatu wilayah, ditentukan oleh sistem transportasi yang handal dan berkemampuan tinggi. Sistem transportasi terdiri dari sarana dan prasarana yang didukung oleh tata cara pelaksanaan dan sumber daya manusia yang membentuk jaringan prasarana dan jaringan pelayanan. Kota Palangka Raya sebagai ibukota Provinsi Kalimantan Tengah dengan letak geografis berada ditengah atau pusat dari rute perjalanan / perpindahan transportasi dari hampir setiap Kabupaten di Provinsi Kalimantan Tengah. Hal ini menyebabkan adanya potensi peningkatan aktivitas transportasi di Kota Palangka Raya bersamaan dengan perkembangan masingmasing pertumbuhan ekonomi di Kabupaten/Kota di Provinsi Kalimantan Tengah. Sehingga apabila tidak dikelola dengan baik sistem transportasi di Kota Palangka Raya dapat menimbulkan kemacetan kedepannya. Akibat tidak seimbangnya demand dan supply karena tidak efektifnya sistem pengelolaan tranportasi yaitu pertumbuhan jumlah kendaraan dengan kapasitas prasarana transportasi yang ada. Untuk mengatasi hal tersebut maka perlu dilakukan kajian mengenai implementasi fasilitas Intelligent Transportation System (ITS) di Kota Palangka Raya sesuai dengan perkembangan teknologi era industri 4.0 yang memungkinkan perkembangan teknologi informasi dan telekomunikasi menjadi semakin maju. Sehingga dapat membuka peluang untuk pengembangan prasarana yang dapat mendukung terlaksananya sistem transportasi yang lebih efektif dan efisien. Terkait dengan hal tersebut maka fasilitas Intelligent Transportation System (ITS) yang telah diterapkan di Kota Palangka Raya dan rekomendasi fasilitas Intelligent Transportation System (ITS) yang dapat diterapkan di Kota Palangka Raya

\section{KAJIAN PUSTAKA}

\section{Sistem Transportasi}

Transportasi menurut Miro (2012) secara umum dapat diartikan sebagai usaha pemindahan atau pergerakan orang atau barang dari suatu lokasi yang disebut lokasi asal, ke lokasi lain yang biasa disebut lokasi tujuan, untuk keperluan tertentu dengan mempergunakan alat tertentu pula. Dari pengertian ini tranportasi mempunyai beberapa dimension seperti:

a. Lokasi (asal dan tujuan)

b. Alat (teknologi)

c. Keperluan tertentu di lokasi tujuan seperti ekonomi sosial dan lain-lain.

\section{Klasifikasi Jalan}

Klasifikasi menurut fungsi jalan terbagi atas:

\section{a. Jalan Arteri}

Jalan yang melayani angkutan utama dengan ciri perjalanan jarak jauh, kecepatan rata - rata tinggi dan jumlah jalan masuk dibatasi secara efisien.

\section{b. Jalan Kolektor}

Jalan yang melayani angkutan pengumpul/ pembagi dengan ciri - ciri perjalanan jarak sedang, kecepatan rata - rata sedang dan jumlah jalan masuk dibatasi.

\section{c. Jalan Lokal}

Jalan yang melayani angkutan setempat dengan ciri - ciri perjalanan jarak dekat, kecepatan ratarata rendah dan jumlah jalan masuk tidak dibatasi.

\section{Kinerja Jalan}

Kinerja ruas jalan merupakan suatu pengukuran kuantitatif yang meng-gambarkan kondisi tertentu yang terjadi pada suatu ruas jalan. Umumnya dalam menilai suatu kinerja jalan dapat dilihat dari kapasitas, derajat kejenuhan (DS), kecepatan rata-rata, waktu perjalanan, tundaan dan antrian melalui suatu kajian mengenai kinerja ruas jalan. Ukuran kualitatif yang menerangkan kondisi operasional dalam arus lalulintas dan persepsi pengemudi tentang kualitas berkendaraan dinyatakan dengan tingkat pelayanan ruas jalan.

\section{Tingkat Pelayanan (LOS)}

Perilaku lalu lintas diwakili oleh tingkat pelayanan (LOS), yaitu ukuran kualitatif yang mencerminkan persepsi para pengemudi dan penumpang mengenai karakteristik kondisi operasional dalam arus lalu lintas. Tingkat pelayanan adalah kemampuan ruas jalan dan/atau persimpangan untuk menampung lalu-lintas pada keadaan tertentu. 
Enam tingkat pelayanan diabatasi untuk setiap tipe dari fasilitas lalu lintas yang akan digunakan dalam prosedur analisis, yang disimbolkan dengan huruf $\mathrm{A}$ sampai dengan $\mathrm{F}$, dimana Level of Service (LOS) A menunjukkan kondisi operasi terbaik, dan LOS F paling jelek. Kondisi LOS yang lain ditunjukkan berada diantaranya.

\section{Pengertian Intelligent Transport System (ITS)}

Intelligent Transportation System (ITS) dapat diartikan sebagai alat kontrol, informasi dan peningkatan sistem informasi atau komunikasi yang memungkinkan peningkatan kinerja secara signifikan dalam arus lalu lintas dan efisiensi transportasi barang, penumpang, keselamatan serta keamanan transportasi selain itu untuk memastikan peningkatan pelayanan penumpang. Sehingga konsep penerapan Intelligent Transportation System (ITS) digunakan untuk penyelesaian masalah transportasi termasuk permasalahan transportasi di Kota besar. Serta diharapkan mampu memberikan solusi dan melakukan pendekatan terhadap peningkatan kebutuhan transportasi secara efektif dan efisien.

\section{Jenis Intelligent Transportation System (ITS)}

Secara umum, teknologi ITS yang telah berkembang di dunia terdiri dari:

\section{a. Advance Navigation System/Advanced Traveller Information System}

Tujuannya adalah untuk panduan kendaraan untuk mendapatkan rute jalan yang optimal. Umumnya berbentuk peta digital berbasis Geographic Information System (GIS).

\section{b. Advance Traffic Management System}

Aplikasi ini memberikan informasi real time tentang lalu lintas kepada pengguna jalan. Disamping itu juga memberi informasi jika terjadi hambatan/kecelakaan pada rute yang ditempuh. Input data diperoleh dari: CCTV, traffic analyzer, traffic counter, dsb. Sedangkan outputnya melalui: Variable Message Sign (VMS), radio, call centre, dsb.

\section{c. Incident Management System}

Aplikasi ini digunakan untuk mendeteksi kejadian darurat seperti kecelakaan, longsor/bencana lainnya. Sensor pada traffic management system akan memberikan informasi berupa tingkat kecelakaan, jumlah ambulan yang diperlukan, tenaga medis yang harus dikirim, dsb. Informasi duteruskan otomatis ke rumah sakit, pemadam kebakaran.

\section{d. Advance For Save driving}

Pada aplikasi ini kendaraan dilengkapi sejumlah sensor yang mengarahkan pengemudi berkendara dengan aman. Manfaat dari sensor dan komputer pada kendaraan adalah memberitahukan kepada pengemudi apabila tanpa sengaja pengemudi melakukan hal-hal: jarak dengan kendaraan lain terlalu dekat, berada di lajur jalan yang salah, kecepatan terlalu tinggi.

\section{e. Advanced Bus Information System}

Aplikasi ini dapat memberikan informasi waktu kedatangan bus. Disamping itu juga dapat memberitahukan kepada pengemudi apabila tanpa sengaja pengemudi melakukan hal-hal: jarak dengan kendaraan lain terlalu dekat, berada di lajur jalan yang salah, kecepatan terlalu tinggi. Mengendalikan sistem angkutan umum secara terpusat (fleet management).

\section{Penerapan ITS di Perkotaan Indonesia}

Beberapa penerapan teknologi Intelligent Transportation System lainnya di Indonesia yang sudah diterapkan antara lain Area Traffic Control System (ATCS), National Traffic Management Center (NTMC-Polri), E-Toll Road Payment dan Advanced Traveller Information System (ATIS).

\section{METODE PENELITIAN}

Penelitian ini bertujuan untuk menganalisis penerapan fasilitas Intelligent Transportation System (ITS). Pendekatan yang digunakan dalam penelitian ini yaitu kualitatif. Metode kualitatif merupakan metode yang digunakan untuk meneliti fakta yang terjadi dilapangan, dimana teknik pengumpulan data dilakukan secara triangulasi, analisis deskripsi dan analisis data bersifat induktif/kualitatif.

Lokasi penelitian ini dilaksanakan di Kota Palangka Raya. Pelaksanaan penelitian ini hanya berfokus pada penerapan fasilitas Intelligent Transportation System (ITS) yang ada di Kota Palangka Raya. Proses awal dari penelitian ini dengan mengumpulkan literatur atau studi pustaka 
pada penelitian terdahulu berupa kajian teori-teori yang dapat mendukung penelitian ini. Teori tersebut didapat dari beberapa sumber buku, artikel, peraturan yang berlaku, tulisan dari internet dan sumber lainnya. Selanjutnya pada tahapan kedua dilaksanakan metode pengumpulan data primer dan sekunder. Pengumpulan data primer dapat dilakukan dengan observasi, studi dokumentasi. Data sekunder adalah data-data teknis berupa penerapan fasilitas Intelligent Transportation System (ITS) di Kota Palangka Raya.

\section{HASIL DAN PEMBAHASAN}

\section{Gambaran Umum Kota Palangka Raya}

\section{Sarana Dan Prasarana Transportasi}

Jaringan jalan di Provinsi Kalimantan mengalami peningkatan panjang jalan hanya terjadi pada jalan Kabupaten/Kota pada rentang waktu Tahun 2009 dan Tahun 2012. Total panjang jalan provinsi untuk tahun 2012 adalah 1.708 kilometer sedangkan untuk panjang jalan yang berstatus jalan Kabupaten/Kota adalah sebesar 10.625 kilometer.

Untuk sarana transportasi jalan Perkembangan jumlah Kendaraan Bermotor di Provinsi Kalimantan Tengah mengalami peningkatan pada masing-masing moda transportasi dengan total prosentase peningkatan sebesar $10 \%$ dimana jumlah tersebasr pada moda sepeda motor dengan prosentase peningkatan sebesar $21,6 \%$.

Keselamatan transportasi jalan, untuk angka kecelakaan di Provinsi Kalimantan Tengah saat ini masih cukup tinggi, sebagaimana dilaporkan dalam data kepolisian Republik Indonesia jumalah kecelakaan mencapai 1.028 kejadian. Dari jumlah korban kecelakaan sebanyak 1873 orang, 453 orang diantaranya meninggal dunia, 281 orang mengalami luka berat, 1.139 orang mengalami luka ringan.

Dari data terlihat bahwa perkembangan kendaraan bermotor semakin meningkat tiap tahun. Hal ini menyebabkan menurunnya minat pengguna angkutan umum di Kota Palangka Raya karena masyarakat lebih memilih angkutan pribadi. Di Kota Palangka Raya pada Tahun 2019 sudah dioperasikan Bus Rapid Transit (BRT) yang mempunyai dua koridor dalam melayani masyarakat. Diharapkan dengan adanya BRT minat masyarakat terhadap angkutan umum meningkat. Data kecelakaan lalu lintas juga masih tinggi di Kota Palangka Raya hal ini menunjukkan bahwa keselamatan transportasi di Kota Palangka Raya masih belum optimal.

\section{Kinerja Ruas Jalan}

Menurut hasil analisis dari Balai Transportasi Darat bahwa kinerja ruas jalan di beberapa simpang di Kota Palangka Raya menunjukkan bahwa derajat kejenuhan secara umum masih dalam tataran baik dan mampu melayani dengan baik kecuali pada beberapa lokasi yang memang menunjukkan nilai derajat kejenuhan diatas 0,8 .

\section{Kecepatan}

Menurut hasil analisis dari Balai Transportasi Darat bahwa kecepatan perjalanan beberapa ruas jalan ditemukan kondisi rata-rata cukup rendah. Meski demikian beberapa ruas juga mempunyai kecepatan yang cukup tinggi untuk jalan di kawasan perkotaan.

Sesuai rata-rata kecepatan perjalanan yang ada sebesar 27,67 km/jam, menunjukkan bahwa waktu tempuh kendaraan di dalam segmen atau ruas jalan cukup lama sehingga diperlukan upaya untuk meningkatkan kecepatan perjalanan dan meningkatkan waktu tempuh sehingga tingkat tundaan dalam perjalanan dapat diminimalkan.

\section{Penerapan ITS di Kota Palangka Raya}

Berdasarkan hasil wawancara dengan Balai Transportasi Darat di Kota Palangka Raya diketahui bahwa penerapan fasilitas ITS yang diterapkan di Kota Palangka Raya berupa jenis Area Traffic Control System (ATCS) atau Sistem Kendali Lalu lintas Kendaraan adalah pengendalian lalu lintas dengan menyelaraskan waktu lampu merah pada jaringan jalan raya dari sebuah kota. Pengaturan lalu lintas melalui sistem ini memerlukan parameter jumlah kendaraan dan waktu tempuh kendaraan. Dan penerapan ATCS ini dimulai pada Tahun 2018.

Adapun rujukan dinas terkait menerapkan sistem ATCS berdasarkan rujukan Peraturan Menteri Perhubungan Indonesia Nomor PM 96 
Tahun 2015 tentang Pedoman Pelaksanaan Kegiatan Manajemen dan Rekayasa Lalu Lintas.

\section{Manfaat dan Jenis Area Traffic Control System (ATCS)}

Adapun manfaat yang diperoleh dengan pengembangan ATCS ini adalah sebagai berikut:

- Meningkatkan keselamatan lalu lintas;

- Mengurangi tingkat pemakaian bahan bakar karena berkurangnya waktu perjalanan;

- Secara tidak langsung mengurangi polusi udara dan kebisingan;

- Meningkatkan kualitas kehidupan perkotaan;

- Memberikan kelancaran pelayanan bagi kendaraan darurat (pemadam kebakaran, ambulans, dll);

- Mengurangi jumlah petugas pengatur lalu lintas dipersimpangan jalan.

Jenis-jenis ATCS:

Berdasarkan teknologi yang digunakan maka teknologi ATCS dibagi menjadi 3 yaitu:

1. ATCS yang tidak responsif

Menggunakan Alat Pemberi Isyarat Lalu Lintas (APILL) yang dioperasikan, secara fixed setting berdasarkan data survey (at the moment) tanpa ada sinkronisasi terhadap laju traffic aktual pada simpang.

2. ATCS yang semi responsif

Menggunakan detector kendaraan pada Alat Pemberi Isyarat Lalu Lintas (APILL) dan melakukan sinkronisasi berdasarkan trafik aktual pada simpang yang bersangkutan saja, tetapi tidak ada pengelolaan lalulintas secara menyeluruh dan terkoordinasi di seluruh wilayah (region).

3. ATCS yang fully responsif

Memiliki pusat pengendalian, Alat Pemberi Isyarat Lalu Lintas (APILL) berhubungan dengan komputer dan dilengkapi dengan alat pencatat pergerakan arus lalu lintas berupa detektor, sehingga program pengaturan nyala lampu besarnya dapat berubah-ubah sesuai kondisi arus lalu lintas secara real time dan dapat dikoordinasikan secara serentak dan menyeluruh dari ruang Traffic Management Center (CCRoom).

\section{Lokasi Area Traffic Control System (ATCS) di Kota Palangka Raya}

Area Traffic Control System (ATCS) yang sudah terpasang dan beroperasi di Kota Palangka Raya terdapat pada beberapa lokasi di simpang jalan bersinyal, yaitu:

1. Simpang 3 Katedral: jl. Kahayan dan Jl. A. Cilik Riwut

2. Simpang 3 Korem: Jl.Imam Bonjol dan Jl. Let. Jend. Suprapto

3. Simpang 4 Bundaran Kecil: Jl. Imam Bonjol, Jl. G.Obos, Jl. Diponegoro, Jl. RTA. Milono

4. Simpang 3 Jalan Antang: Jl. Antang, Jl. Cilik Riwut

Titik-titik lokasi simpang dalam perencanaan ATCS Kota Palangkaraya Provinsi Kalimantan Tengah dapat dilihat pada gambar berikut:

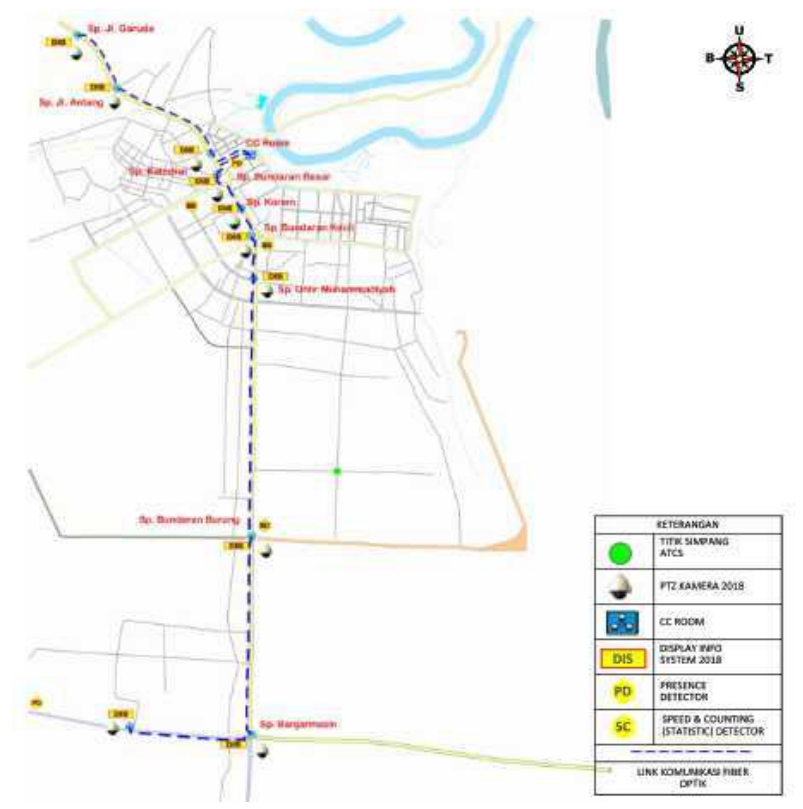

Gambar 1. Titik-titik lokasi simpang dalam perencanaan ATCS Kota Palangkaraya

Sumber: Balai Transportasi Darat Kalimantan Tengah

Adapun ATCS yang dipasang sebagai berikut:

1. Tiap kaki simpang dipasang detektor kendaraan.

2. Tiap simpang dipasang IP kamera untuk pemantauan, Situasi lalu lintas

3. Perangkat VMS atau DIS (Display Info System) yang dapat menampilkan counting down pada titik simpang yang terhubung dengan system ATCS. 
4. APILL PLN 220 Volt, bisa digunakan sepenuhnya dengan cara mengganti control dan menambah perangkat pendukung ATCS.

5. Jaringan data menggunakan Perangkat Fiber Optic.

6. Lokasi Pusat kendali (CC-Room) berada di Kantor Dinas Perhubungan Provinsi, dan dihubungkan dengan CC ROOM Kota Palangkaraya Provinsi Kalimantan Tengah.

Berdasarkan hasil wawancara dengan pihak Balai Pengelola Transportasi Darat Wilayah XVI Provinsi Kalimantan Tengah bahwa pemasangan ATCS di Kota Palangka Raya mulai diterapkan pada tahun 2018 dan peraturan tentang ITS yang diterapkan di Kota Palangka Raya yaitu ATCS merujuk pada Peraturan Menteri 96 Tahun 2015 Tentang Pedoman Pelaksanaan Kegiatan Manajemen dan Rekasaya Lalu Lintas

\section{Koordinasi Sinyal Lampu Lalulintas Antar Simpang}

Menurut Pedoman Sistem Pengendalian
Lalu Lintas Terpusat No.AJ401/1/7/1991
Keputusan Direktur Jendral Perhubungan Darat,
dasar pendekatan dari perencanaan sistem
terkoordinasi pengaturan lalu lintas sepanjang
suatu jalan arteri adalah bahwa
kendaraankendaraan yang lewat jalan tersebut akan
melaju dalam bentuk iring-iringan dari satu
simpang ke simpang berikutnya.

Selain itu, fungsi dari sistem koordinasi sinyal adalah mengikuti volume lalu lintas maksimum untuk melewati simpang tanpa berhenti dengan mulai waktu hijau (green periode) pada simpang berikutnya mengikuti kedatangan dari kelompok (platoon).

Dari data hasil analisis perbedaan arus kendaraan dengan asumsi menggunakan ATCS dengan kecepatan rata-rata rencana $35 \mathrm{~km} / \mathrm{jam}$ untuk setiap jarak simpang dihasilkan efisiensi waktu sebesar 1,84 jam per hari atau akan menghemat waktu sebesar $23 \%$.

\section{PENUTUP}

\section{Kesimpulan}

Berdasarkan hasil penelitian yang telah dilaksanakan, maka dapat disimpulkan sebagai berikut:

1. Penerapan fasilitas Intelligent Transportation System (ITS) di Kota Palangka Raya berupa Area Traffic Control System (ATCS) yaitu sistem pengendalian lalu lintas secara terkordinasi di suatu kawasan /wilayah / area / daerah. Manfaat ATCS di simpang bersinyal jalan nasional Kota Palangka Raya meningkatkan efisiensi waktu sebesar 1,84 jam per hari atau akan menghemat waktu sebesar 23 $\%$ dari tundaan di simpang bersinyal.

2. Untuk mengoptimalkan kinerja angkutan umum (BRT) dan keselamatan lalu lintas serta adanya kerjasama antara stakeholder agar peningkatan sistem transportasi terintegrasi dengan baik maka ATCS diharapkan dapat juga diterapkan pada angkutan umum di kota Palangka Raya.

\section{Saran}

Berdasarkan penelitian yang dilakukan, maka saran yang dapat peneliti sampaikan yaitu Kota Palangka Raya sudah selayaknya melakukan penerapan Area Traffic Control System (ATCS) karena di beberapa ruas jalan atau simpang bersinyal memiliki waktu tundaan yang lama.

\section{DAFTAR PUSTAKA}

Direktorat Jendral Bina Marga. (1997). Manual Kapasitas Jalan Indonesia. Indonesia Departemen Pekerjaan Umum.

Hobbs, F. D. (1995). Perencanaan Dan Teknik Lalu Lintas. Edisi ke-2, Universitas Gadjah Mada, Yogyakarta.

Keputusan Menteri Perhubungan No KP.430 Tahun 2015 tentang Rencana Strategis Kementerian Perhubungan, Kementerian Perhubungan.

Suyuti, R. (2012) Implementasi Intelligent Transportation System (ITS) Untuk Mengatasi Kemacetan Lalu Lintas Di DKI Jakarta. .Jurnal Konstruksia vol 3 no 2012 
Implementasi Fasilitas Intelligent Transportation System..., Devia ${ }^{(1)}$, Prihanika $^{(2)}$

Tamin, O.Z. (2000) Perencanaan dan Pemodelan Transportasi, Edisi 2, Penerbit ITB, Bandung.

Pamudi \& Suryani, E. (2018) Penerapan Sistem Dinamik dalam Intelligent Transport Systems (ITS) untuk Meningkatkan Efektifitas, Efisiensi, dan Safety (Study Kasus Dinas Perhubungan Kota Surabaya) Jurnal Ilmiah Bidang Teknologi Informasi dan Komunikasi Vol.3 No.1, Januari 2018, P-ISSN : 2502-3470, EISSN : 2581-0367

Yustina, Niken R H. (2013). Optimalisasi Penerapan ATCS (Area Traffic Control System) Dalam Pengoperasian Trans Jogja Bus Priority Pada Simpang Bersinyal. Universitas Gadjah Mada. Diunduh dari http://etd.repository.ugm.ac.id/ 